\title{
Possible Causes \& Solutions of Traffic Jam and Their Impact on the Economy of Dhaka City
}

\author{
Khaled Mahmud $^{1}$, Khonika Gope ${ }^{1}$ \& Syed Mustafizur Rahman Chowdhury ${ }^{2}$ \\ ${ }^{1}$ Institution of Business Administration, University of Dhaka, Dhaka, Bangladesh \\ ${ }^{2}$ Department of Business Administration, Northern University Bangladesh, Bangladesh \\ Correspondence: Khaled Mahmud, Institution of Business Administration, University of Dhaka, Dhaka 1000, \\ Bangladesh. E-mail: khaled@iba-du.edu
}

$\begin{array}{ll}\text { Received: February 7, } 2012 & \text { Accepted: February 24, } 2012 \quad \text { Online Published: May 24, } 2012 \\ \text { doi:10.5539/jms.v2n2p112 } & \text { URL: http://dx.doi.org/10.5539/jms.v2n2p112 }\end{array}$

\begin{abstract}
Dhaka, capital of Bangladesh, is the most densely populated city in the whole world. More than twelve million people live in Dhaka city. Day by day the number is increasing and most part of Dhaka is badly affected by huge traffic jam. Faulty traffic signaling systems, inadequate manpower, narrow road spaces and overtaking tendency of drivers create pro-longed traffic congestions. Due to traffic jam a substantial portion of working hours have to be left on streets which indirectly put adverse impact on economy. It causes serious air pollution and noise pollution and thus worsens the overall environmental condition. To reduce traffic jam, government can consider construction of roads through east-west connection of Dhaka city, construction of circular embankment-cum-road along the periphery of Dhaka city, grade separated road network system, bus Rapid Transit (BRT) system, and Metro-Rail system. By reducing traffic jam, this city can play a very important role by ensuring healthy environment free from noise and pollution.
\end{abstract}

Keywords: traffic jam, Bangladesh, economy, environment, Dhaka city

\section{Introduction}

Dhaka city's traffic system is considered to be one of the most chaotic ones in the world. The residents are compelled to undergo physical stress and suffer financial losses in terms of man-hours lost on working days. The media, both print and electronic, have been constantly highlighting the sufferings of the commuters in Dhaka city because of the nagging traffic problem. Yet no solution to the problem, apparently, is in sight, at least, in the short and medium terms, though a lot has been said and a big-enough programme, undertaken with the assistance from a multilateral lender to improve the traffic situation of the capital city in recent years.

Various attempts were taken by previous governments including special meeting with the agencies concerned to devise means to help reduce the intensity of traffic problem in Dhaka city. Some tangible improvements were assured within the shortest possible time. But, in fact nothing has happened with the traffic police remaining indifferent, in many cases, to their usual duty. The drivers of buses and trucks and the rickshaw-pullers continue to be as defiant as before. In the past politicians were often blamed partially for the chaotic traffic because of their alleged involvement in billion-taka toll collection from bus and truck owners and bus terminals. The advisers of the caretaker government were believed to be clean in this respect. Yet, there was no improvement in the traffic situation.

The public buses are still ignoring the authorized bus stoppages and picking up and dropping passengers from any point -- even from the middle of the road. At the bus stoppages, the drivers park buses in a haphazard manner blocking normal traffic movement. Then again, the buses do very often overtake other vehicles from the wrong side. Over 95 per cent of the buses plying on different routes of Dhaka city do not comply with requirements under the Motor Vehicles Act (MVA). They do not have back lights, indicators etc. The on-duty traffic sergeants, deliberately or otherwise, overlook violation of MVA and other traffic rules, for reasons best known to them.

Against this backdrop, the Dhaka City Corporation (DCC), according to a report published, is considering to take a move for expansion of the electronic signaling system to 'ease' traffic congestion in the city. A good number of such signaling devices have been out of order more than a year. The DCC is responsible for installation and 
maintenance of the traffic signaling system and the traffic division of the Dhaka Metropolitan Police (DMP) uses the same for 'smooth' traffic movement. The question is: How effective are the electronic traffic signals? In most traffic intersections having installed traffic signaling system, the on-duty traffic policemen resort to the manual control of vehicular movement, on the plea that the system is ineffective during rush hours. This could be mainly due to the absence of a synchronized operation of the entire electronic traffic signaling system.

But the basic problem of the city's traffic system is that the existing road network is incapable of holding the ever-increasing number of motor vehicles. Thus, the solution lies not in the installation of electronic signals or increase in the number of traffic police. The effective use of the two might provide some temporary relief but not a permanent solution. Some alternatives such as elevated expressways, subways and multi-layer fly-over across the city hold the key to solving the problem. The new government does need to consider some strong steps as one of its priorities to help address Dhaka city's chronic traffic problem.

More than 7 hundred thousand rickshaws ply the city road, but only 75 thousand have legal number. From time to time attempts are made to reduce the number, but the initiative usually produces very slow impacts. Government has also tried many solutions like flyovers, bridges, circular water ways. But, it still it needs a lot of planning. Traffic jam is obstructing trade and commerce. Illegal parking is another reason for traffic jam. Cars, trucks and other vehicles are parked almost everywhere. Faulty traffic signalling systems, inadequate manpower and narrow road spaces and overtaking tendency of drivers create pro-longed traffic congestions and intensify sufferings of commuters keeping people motionless as well as creating suffocating condition in the streets.

Due to traffic jam, we are suffering economically, physically and even mentally. So, we want to work on this vital issue to find out the causes and suggest some realistic possible solutions and their economical impact on the people of Dhaka city.

\section{Literature Review}

Md. Asadullah Khan has described the scenario of traffic jam in Dhaka city in Daily Star with the title "When shall we get rid of Dhaka city traffic jam?”, published on October 20, 2007 (Khan, 2007). According to him with a huge fleet of cars, buses and all other types of vehicles gridlocked near a rail gate or road intersection sometimes even for 30 minutes at a stretch, Dhaka city's traffic congestion problem has assumed an alarming proportion. People are afraid to get out of their houses because the journey from home to office or business centre takes away the vital hours that he could devote to his work. Other than being late in the offices, work places or on any scheduled appointments, mental disgust, exhaustion and loss of effective man hours is a colossal drain on the resources of the whole country. The road scene in Dhaka is something awesome especially at important crossings like Bishwa Road, Mohakhali-Tejgaon, Panthapath-Bijoy Sarani, Sonargaon Hotel crossing linking Tejgaon Industrial area and Farmgate crossing, Hatirpool, New Market, Gulistan, Bangladesh Bank and Hatkhola crossing near the Ittefaq office. According to some source of the DCC there are about one lakh licenced rickshaws in the city but unofficially perhaps four lakh rickshaws are plying on the city roads. In absence of any separate lanes for rickshaws on most of the roads, they occupy the whole road space and interfere with the movement of the mechanised vehicles. Due to traffic congestion created by these rickshaws on the same road lane, the fast moving transports can hardly make 15 to $20 \mathrm{~km}$ per hour.

Md. Masud Karim (1997) found that limited resources, invested for the development of transport facilities, such as infrastructure and vehicles, coupled with the rapid rise in transport demand, existence of a huge number of non-motorized vehicles on roads, lack of application of adequate and proper traffic management schemes are producing severe transport problems in almost all the urban areas of Bangladesh. Worsening situation of traffic congestion in the streets and sufferings of the inhabitants from vehicle emissions demand extensive research in this field.

According to Nasrin Khandoker and Jonathan Rouse (2004), Congestion in Dhaka has been a growing problem during the last 15 years. In around 1992, the Government of Bangladesh completed a study called 'The Greater Dhaka Metropolitan Area Integrated Transport Study', funded by the United Nations Development Program. The study recommended an immediate action plan and a long-term strategy to improve transport infrastructure in the Greater Metropolitan area of Dhaka. In response to this, the Government sought assistance from the World Bank to help fund the Dhaka Urban Transport Project (DUTP). Now being implemented, project objectives include addressing urgent policy issues, infrastructure development, capacity building and resettlement of displaced people. Efficient urban management, cost recovery, community participation and involvement of the private sector were identified as the key tools for providing efficient, affordable and sustainable transport (Kazi, 2003).

A.H. Jaffor Ullah (2001) admits this fact that traffic hardly moves in Dhaka's main artery during rush hours. Many folks from mercantile community would prefer to leave their house late in the morning to simply avoid the 
all too familiar rush hour traffic jams. But their number is few and far between. Most Dhaka folks who work in government offices, schools, and other offices have no choice but to hit the road during the morning rush hour. These folks obviously take the brunt of rush hour traffic jam. If one thinks that it is an exaggerated statement, then one should climb up to one of those over bridges near Farmgate, Karwan Bazaar, or Bangla Motors to take a peek at any of the ubiquitous traffic jams. One could see the crawling vehicles, as far as the eyes would allow one to see, lining up the avenues near the bustling intersections. Come to think of it, there are quite a few intersections near Farmgate. This clearly indicates that Dhaka's road system is unplanned from the very beginning.

To find out some innovative solutions, Bangladesh Inland Water Transport Authority (BIWTA) conducted a research on "Water way around Dhaka City" (Desh Upodesh Ltd., 2001). According to them, if alternative water way can be introduced around the Dhaka city, traffic jam can be reduced. Government has tried that. But due to some environmental and seasonal factors of weather and lower level of water in water ways, this project failed. Later another project was done from BUET Water Resources Engineering Department on feasibility study for development of circular water way (Bari, 2008). They are proposing a new way to introduce circular water way in Dhaka city.

Shuichi and Hironao (2003) have shown in their study that by improving traffic signalling strategies can improve the traffic situation of the street cars. According to them, their proposed signalling strategy improves the traffic situation of the street cars. Same signalling system can be implemented in Dhaka City to improve our traffic system.

Syed Saiful Alam Shovan (2008) has shown interesting findings on fuel consumption and environmental impact of rickshaw banning in Dhaka City. Most trips in Dhaka are short in distance, usually one to five kilometres. These trips are perfect of Rickshaws. Rickshaws are cheap and popular mode of transport over short distances. Rickshaws are safe, environmentally friendly and do not rely on fossil fuels. In Dhaka alone, Rickshaw pullers combine to earn 20 million taka a month. Rickshaws are ideal for urban settings because they can transport a relatively large number of passengers while taking up a small portion of the road. In 1998 the data showed that Rickshaws took up $38 \%$ of road space while transporting $54 \%$ of passengers in Dhaka. The private cars on the other hand, took up $34 \%$ of road space while only transporting $9 \%$ of the population (DUTP, 1998). This data does not include the parking space on roads that cars take up in Dhaka. If included this would further raise the amount of space taken up by private cars. Every year the Rickshaw saves Bangladesh 100 billion taka in environmental damage. The government makes many efforts to reduce traffic congestion in Dhaka but with no success. Blaming Rickshaws for traffic congestion and subsequently banning them from major roads has not had the desired affect. Traffic is still as bad now as it was before the Rickshaws were banned on major roads.

Prskawetz, Leiwen and O’Neill (2004) has observed that demographic characteristics of the households can produce important effects to the overall demand of the automobiles, through the combined effects of differences of the automobile demands (based on the household type) and changes of the population composition in the future (also based on the household type). Considering the household head, both the automobile ownership and the automobile use have the similar standard: there is an increase until the intermediate ages and a decrease after these ages. The household size affects directly the automobile ownership and use; part of this effect reflects the age effect. This can be explained as follows: households of smaller size are most likely of being commanded by younger or older persons than by persons with intermediate ages; once the automobile ownership and use are low for younger and older persons.

Recently there is a study in Brazil of environmental impact due to automobiles (Fioravante et al, 2009). Due to demographic changes that have been occurred, the article projects the number and composition of households of Belo Horizonte (Brazil) by household size and marital status and age of reference person, using a multidimensional model developed by Yi (1991) that considers the interdependence between demographic events. However the ambient impact did not occur with the same intensity, because some old vehicles were substituted by new ones that have lower emission of pollutants.

So, according to the knowledge reviews that we have covered here, actually are showing that due to lack of effective planning and proper focusing on the issues of traffic jam in Dhaka city, it has become a mammoth problem now a days. Adequate research and some alternative solutions might give us some hope and light to solve the traffic problem in Dhaka city. 


\section{Objectives}

\subsection{Broad Objective}

Broad objective is to find out the possible causes of traffic jam in Dhaka City and to figure out the possible solutions.

\subsection{Specific Objectives}

Objective and Scope of the study is limited to -

i. Find out all the possible causes of traffic jam in Dhaka city,

ii. Find out the all possible solutions for the traffic jam in Dhaka city,

iii. Rank the problems and solutions according to their impacts and importance,

iv. Economic impact and benefit analysis of the problems and solutions on the basis of:

a. Fuel Consumption,

b. Transportation cost,

c. Health related issues,

d. Environment related issues.

\section{Scope of the Study}

Scope of the study is limited to -

i. Find out the probable causes of the traffic jams in Dhaka City only,

ii. Find out possible solutions of the traffic jams in Dhaka City only,

iii. To discuss the economic, environmental and health related issues with help of survey from general people, drivers and expert opinions.

\section{Methodology}

Methodology details are given below:

\subsection{Data Requirement Plan}

Our data is required from all the stakeholders related to traffic jams. According to our plan we have covered

a. People who are suffering traffic jams,

b. Researchers who are working on it and

c. Government officials who are in the organizations to make rules.

\subsection{Data Sources}

We have two types of data sources.

a. Primary Sources and

b. Secondary Sources.

5.2.1 Primary Sources

a. Focused Group discussion

b. Questionnaire survey,

c. Direct observation,

d. Personal Interview.

5.2.2 Secondary Sources

a. Related journals and articles,

b. Website articles,

c. Articles from Government/ Non-government organizations,

d. Previous works on the related issue.

\subsection{Data Collection Mechanism}

i. We have gone through a focused group discussion to get the possible causes of traffic jam. 
ii. We have prepared a structured questionnaire survey. This survey was directly to the people that are facing traffic jams daily.

iii. We have interviewed some government high officials from RAJUK, and DTCB to get to know their views and government plans.

iv. We have talked to faculty members of Civil Engineering and Urban Resource and Planning department, BUET to get to know about the planners view about the traffic jam.

v. We also have talked to the director of Accident Research Institute about the traffic jam issue and get to know some more details about the impact of traffic jam on the population of Dhaka City.

\section{Current Scenario}

\subsection{City of Dhaka}

Dhaka, formerly Dacca and Jahangir Nagar, is the capital of Bangladesh and the principal city of Dhaka District. Dhaka is a mega city and one of the major cities of South Asia. Located on the banks of the Buriganga River, Dhaka, along with its metropolitan area, has a population of over 12 million, making it the largest city in Bangladesh (Statistical Pocket Book, 2008). Dhaka is known as the City of Mosques and renowned for producing the world's finest muslin. As a cosmopolitan city, Dhaka has been the center of Persio-Arabic and Western cultural influences in eastern South Asian Subcontinent. Today it serves as one of the prime centers for culture, education and business in the region.

\subsection{Transportation System of Dhaka City}

Cycle rickshaws and auto rickshaws are the main mode of transport, with close to 400,000 rickshaws running each day - the largest number for any city in the world (Lawson, 2002). However, only about 85,000 rickshaws are licensed by the city government (McGee, 2006; Laskar, 2007). Relatively low-cost and non-polluting cycle rickshaws nevertheless cause traffic congestion and have been banned from many parts of the city. Public buses are operated by the state-run Bangladesh Road Transport Corporation (BRTC) and by private companies and operators. Scooters, taxis and privately owned automobiles are increasingly becoming popular with the city's growing middle class. The government has overseen the replacement of two-stroke engine taxis with "Green taxis" locally called CNG, which run on compressed natural gas (Mushfiqur, 2003).

Dhaka has 1,868 kilometres (1,161 mi) of paved roads (Ahmed, 1986). It is connected by highways and railway links to Chittagong, Khulna, Mymensingh, Rajshahi, Faridpur and Sylhet. Highway links to the Indian cities of Kolkata and Agartala have been established by the BRTC which also runs regular bus services to those cities from Dhaka. The Kamalapur Railway Station and the Airport (Biman Bandar) Railway Station are the main railway stations providing trains on suburban and national routes operated by the state-run Bangladesh Railway (McAdam, 2004). The Sadarghat Port on the banks of the Buriganga River serves the transportation of goods and passengers upriver and to other ports in Bangladesh (Economic and Social Commission for Asia and the Pacific. (2005 Economic and Social Commission for Asia and the Pacific, 2005). The Zia International Airport is the largest and busiest in the nation (Alam, 2003).

\subsection{Transport Media in City of Dhaka}

We have conducted a survey. According to our survey the main transportation mediums that are used in Dhaka City are -
1) Public Bus,
2) Rickshaw,
3) Taxi,
4) Private Car, and
5) Motor cycle.

From figure 1, we can see that the most used transport is Public bus, which is $41 \%$. After public bus, people use mostly rickshaw. It is very popular transportation in Dhaka City, which is used $38 \%$ by people. People use taxi cab or small three wheel taxis also but not that much (11\%). And only $8 \%$ of people use private cars. There are also few bicycle travellers in Dhaka city. 


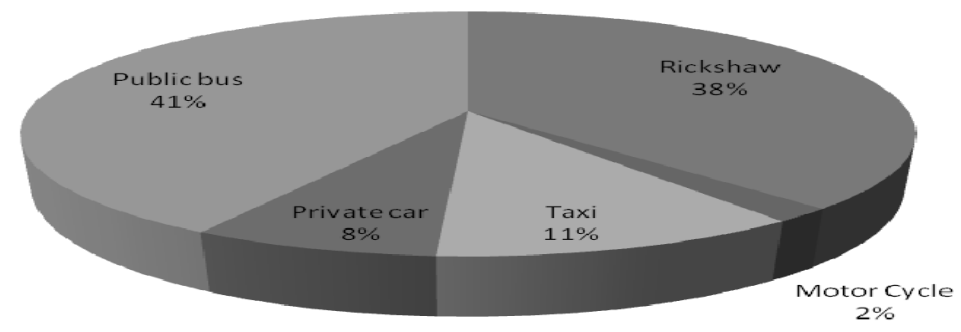

Figure 1. Transport medium in Dhaka City

\subsection{Wastage of Time Due to Traffic Jam}

In Dhaka City Corporation there are around 7 million people and in Dhaka metropolitan there are more than 12 million people. In this mega city, people on an average spend 2.35 hours in the traffic of which 1.30 hours are due to traffic jam. It means they are loosing 1.30 hours everyday due to traffic jam. They are loosing 1.30 man hour of resource every day. It means it takes more than double transportation time.

Figure 2 shows that people are loosing 55\% of their traffic hour during staying in the traffic. They can convert this time into valuable work that might add something to our economy.

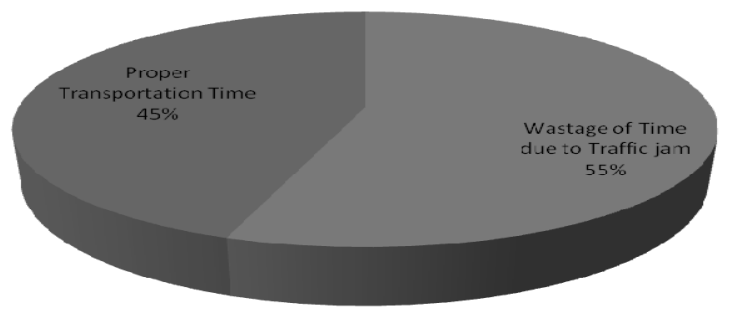

Figure 2. Wastage of time of general people due to traffic jam

Similarly those who are vehicle operator they are also loosing a lot of time due to traffic jam. They are loosing almost three hours due to traffic jams. On an average their daily working hour is slightly over 12 hours. It means they are loosing almost $25 \%$ of their working hour. Figure 3 is showing this.

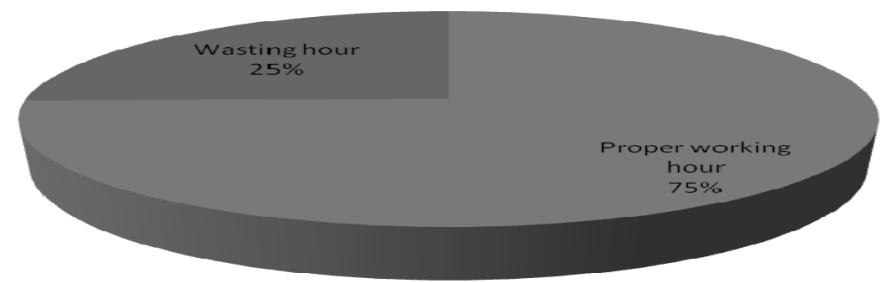

Figure 3. Wastage of time of vehicle operators due to traffic jam

\subsection{Planners vs. Engineers}

Normally two groups are responsible for the planning or operations of traffic in City of Dhaka. And a cool war is always running between planners and engineers. Planners work behind the scene and engineers work in the field.

Planners try to plan for long future whether engineers look for short term solutions. The clash begins here. Planners want to plan first and then implementation whether engineers always want to work fast and have less 
visionary capabilities. But as they work on the field, they hold executive power. Engineers want to work on more projects for their benefits.

This conflict between planners and engineers remains for a longer time and development of traffic system of Dhaka City has a slower progress.

\section{Causes of Traffic Jam}

\subsection{Possible Causes of Traffic Jam}

We will discuss this part from three points of view.

1) General people's point of view,

2) Vehicle operator's point of view and

3) Expert's point of view.

\subsection{Cause Stated by General People}

According to general people there are 12 main causes of traffic jam in the streets of Dhaka City. They are -

1) Traffic rule violation,

2) lack of Planning of city road,

3) Low road space,

4) Unplanned stoppage/ parking,

5) Different speed vehicle,

6) Over population,

7) Rickshaw,

8) Insufficient road,

9) Lack of law implementation,

10) Private car,

11) Important establishments in Dhaka, and

12) Lack or driving training/ sense.

So, according to general people, who apparently are the prime victims of traffic jam, think that Traffic rule violation is the main cause of traffic jam. After that lack of proper planning of the city, inadequate road space, unplanned stoppage or parking, different speed vehicle in the same road, over population, etc. are responsible for causing traffic jam in Dhaka City.

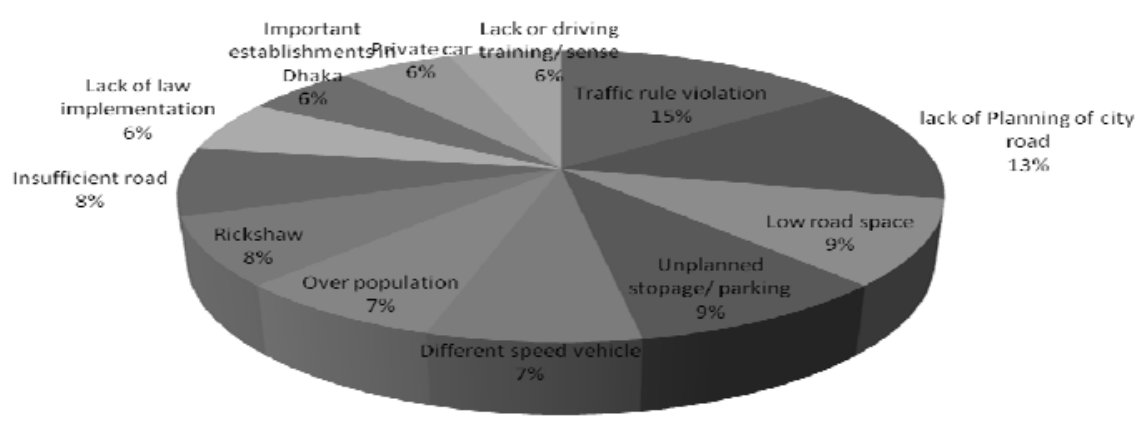

Figure 4. Causes of traffic jam (View of general people)

\subsubsection{Traffic Rule Violation}

Only $70 \%$ of people are aware of traffic rules which are very alarming. Due to this knowledge gap and unwillingness to follow traffic rules people violate traffic rules and that causes traffic jam. 
From figure 5, we can see that only $13 \%$ of people follow traffic rules strictly. On the other hand, $47 \%$ people moderately follow traffic rules and $40 \%$ of people never follow traffic rules. So, this is very apparent that traffic rules violation is one of the main reason that is responsible for traffic jam in Dhaka City.

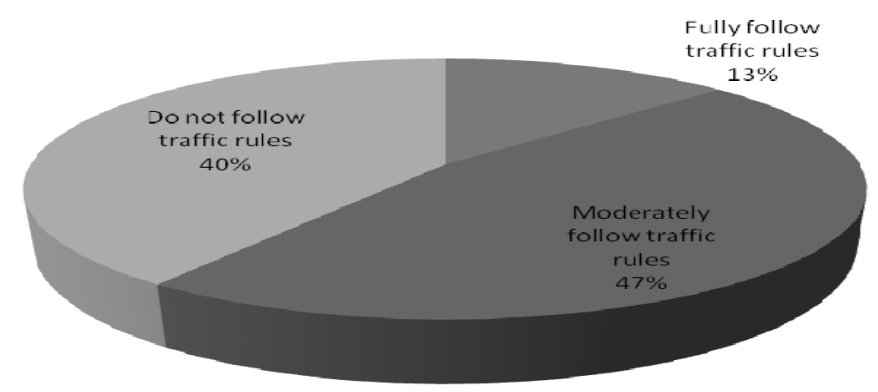

Figure 5. Percentage of traffic rules violation

\subsubsection{Lack of Planning of City Road}

The roads of Dhaka City are not pre planned. As the city needs a road, authority keep making roads. That is why there is no pre plan. And we are suffering traffic jam as an outcome of unplanned city.

\subsubsection{Low Road Space}

Due to unplanned parking and construction materials that are place beside the road, the usable road space becomes low. So, with the low road space it is common that very few vehicles will get the chance to pass through them. It causes traffic jam.

\subsubsection{Unplanned Stoppage/ Parking}

We do not have any planned parking facility over Dhaka City. That is why vehicle operators stop their vehicles in any place, where they need. And it cause traffic jam.

\subsubsection{Different Speed Vehicle}

Slow and fast moving vehicles are running through the same road. As a result, slow moving vehicles are making the fast moving vehicles slow. This is also one of the important reasons of traffic jam.

\subsubsection{Over Population}

It is very apparent that due to heavy population in Dhaka City, traffic load is also huge. This huge population needs to transport from one place to another. As a result enormous traffic load is very common.

\subsubsection{Rickshaw}

Some people think rickshaw is the main cause of traffic jam. Their structure and moving capability is also responsible for traffic jam.

\subsubsection{Insufficient Road}

Due to inadequate space in the Dhaka City according to its population, we have very low road space to offer for this huge population as buildings, offices are consuming a huge portion of lands.

\subsubsection{Lack of Law Implementation}

One important complain against traffic is lack of proper law implementation is also encouraging illegal parking. So, law enforcement should be strict.

\subsubsection{Private Car}

Private car in the roads are also causing traffic jam. As in one private car there are only $2 / 3$ people but the car is taking a lots of space.

\subsubsection{Important Establishments in Dhaka}

All the important offices, famous schools and colleges are in Dhaka City. So, people has to come Dhaka every now and then. This also introduces a lot of floating people in Dhaka, which increase the population of Dhaka and eventually the traffic jam is increased. 


\subsubsection{Lack or Driving Training/ Sense}

And lastly, lack of proper training to the drivers and lack of driving sense are also causing traffic jam. There are also few reasons that we found out through our survey. Very few people think these reasons are also causing traffic jam. Like -

1) Lack of awareness,

2) Not enough space for U turn,

3) Not enough traffic police,

4) Presence of hawkers beside the roads,

5) Huge number of vehicles in the road,

6) Poor signalling system.

\subsection{Cause Stated by Vehicle Operators}

There are six main causes stated by the vehicle operators. They are as follows:

1) Traffic rules violation

2) Excessive vehicle on the road

3) Inefficient traffic police

4) Rickshaw

5) Reckless driving

6) Public bus

So, according to vehicle operators, the main cause of traffic jam is traffic rule violation. 25\% vehicle operator thinks that. Similarly too many vehicles in road and Problems caused due to inefficient traffic police also highly responsible for traffic jams. They also have stated presence of rickshaw, reckless driving of few drivers and public buses are causing traffic jams.

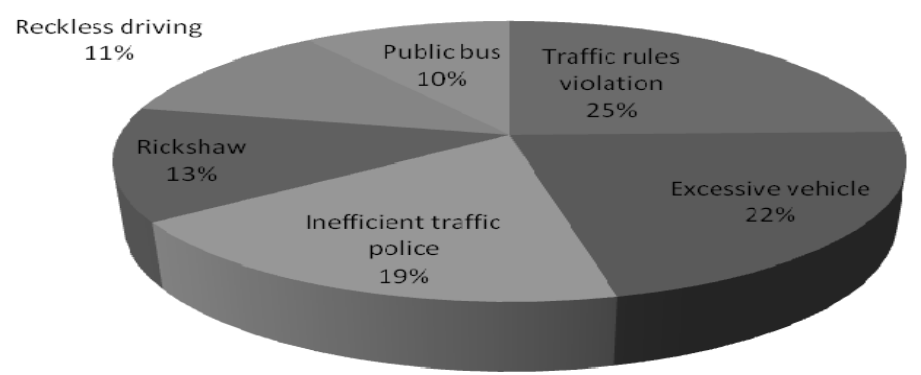

Figure 6. Cause of traffic jam stated by vehicle operators

\subsubsection{Traffic Rule Violation}

$80 \%$ of the vehicle operators are aware of traffic rule. But among them only $27 \%$ strictly follow the traffic rules. $60 \%$ follows traffic rules moderately and 13\% never follow traffic rules. This is very alarming. Figure 7 explains this. 


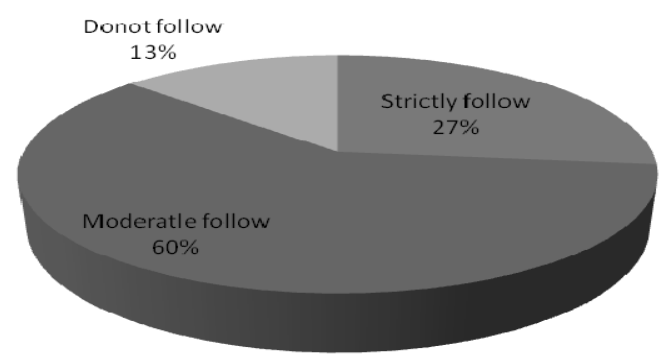

Figure 7. Violation of traffic rules by vehicle operators

\subsubsection{Excessive Vehicle on the Road}

According the vehicle operators there is excessive number of vehicle in the road than it can bear. This is causing traffic jam.

\subsubsection{Inefficient Traffic Police}

Traffic polices are inefficient maintain traffics. Because of their inefficiency and ineffectiveness people are suffering traffic jams.

\subsubsection{Rickshaw}

Presence of rickshaw is also responsible for creating traffic jams. Rickshaws are making fast moving vehicle slower and the movement of rickshaw are well suited for creating traffic jams.

\subsubsection{Reckless Driving}

They also agree that reckless driving of some drivers causes accidents and also creates traffic jam. Due to reckless driving they cause others panic.

\subsubsection{Public Bus}

This is quite interesting that vehicle operators consider public buses are creating traffic jams. They think the drivers of the public buses are reckless and they do not want consider anything. This behaviour of them is one of big reasons for traffic jams. There are also few other causes that vehicle operators think are responsible for causing traffic jams. They are as follows:
1) Parking,
2) Ill road system,
3) U turn,
4) Overbridge shortage,
5) Poor signaling,
6) Truck, and
7) Car parking.

\subsection{Cause Stated by Experts}

From experts point of view, there are various reason from traffic jam in Dhaka City. Among them the main reasons are -

1) Inadequate road length to Dhaka City,

2) Unplanned City growth,

3) Over population,

4) High migration from rural to urban area,

5) Inadequate traffic management,

6) Lack of Integration,

7) Absence of Mass traffic system, 
8) One sided development (North- South development),

9) Footpath occupied by hawkers, and

10) No Parking policy in Bangladesh.

7.4.1 Inadequate Road Length to Dhaka City:

As it is already stated, Dhaka City does not have enough road length to carry all its traffic load.

\subsubsection{Unplanned City Growth}

Yes, it is true that Dhaka City is expanding. But this expansion has no planning. So, buildings are built, markets are made but none is looking at the road space.

\subsubsection{Over Population}

This is obvious reason. Due to high population, we are facing high traffic.

\subsubsection{High Migration from Rural to Urban Area}

This is due to centralization of all important institution in Dhaka. People have to travel Dhaka very frequent. Dhaka is also the city of opportunity. So, people come here to try their fate.

\subsubsection{Inadequate Traffic Management}

It is the similar reason stated by the people. It needs more control management of traffic. Due to lack of proper control management, traffic jam is increasing day by day.

\subsubsection{Lack of Integration}

Too many traffic regulatory authority and lack of integration among traffic regulatory authorities of Dhaka City are one of the major reasons of Traffic jam. Name of few regulatory authority are given below:

1) DCC - Dhaka

2) RAJUK - Rajdhani Unnayan Kortripakkha

3) RHD - Roads and High Ways,

4) BRTA - Bangladesh Road Transportation Authority

5) BRTC - Bangladesh Road Transport Corporation

6) DTCB - Dhaka Transport Coordination Board

7) DMP - Dhaka Metropolitan Police, etc.

\subsubsection{Absence of Mass Traffic System}

For a developing country like ours, we need mass traffic system to distribute the traffic proportionately. Absence of this will definitely put a lot of pressure in traffic channel and cause traffic jam.

\subsubsection{One Sided Development (North- South Development)}

One sided development to North-South is also responsible for causing some jam inside the Dhaka City. If it was all way development then there could be an equal density of traffic all around.

\subsubsection{Footpath Occupied by Hawkers}

Footpath occupying by hawkers make other people walk by the road, which is blocking the space for vehicles and causing traffic jams.

\subsubsection{No Parking Policy in Bangladesh}

Due to lack of parking policy we are suffering traffic jams in Dhaka City.

\subsubsection{Problem of Planner Choice}

The planners like Louis Berger Inc. cannot consider the sentiment, behaviour of Bangladeshi people. So, when they prepare a plan for our traffic, it is just a theoretical plan, not to implement. Because, we have to know well for those we are making the plans. Because of this international planners choice we are also suffering with high ambitious plans.

\subsubsection{Poor Signaling}

Poor Signaling is also responsible for traffic jam. And at some points signal does not work. In that places traffic polices have to work manually. This also cause traffic jams. 


\subsubsection{Short Term Plan}

Sometimes short term planning is made to solve any current situation without looking forward which cause problems afterward. So, situation basis solution for short term is also responsible for traffic jams in Dhaka City.

So, these are the main causes stated by the experts who are dealing traffic issues in academics or in government organizations.

\section{Impact of Traffic Jam on Dhaka City}

The impact of traffic jam on Dhaka City can be viewed in three ways. The ways are -

a. Impact on Economy,

b. Impact on health, and

c. Impact on environment.

\subsection{Impact on Economy}

Traffic jam has great economic impact on Dhaka City. Due to traffic jam we are loosing money in four ways -

a. Loosing man-hours,

b. Extra transportation cost,

c. Extra fuel consumptions,

d. Vehicle operating cost, and

e. Miscellaneous cost.

\subsubsection{Loosing Man-hours}

According to our survey, people in Dhaka work on an average 5.2 days in a week. The average income of people of Dhaka City is 500 US dollar. If we consider 1 dollar is equal to 69 taka. Then per hour income of a people in Dhaka City is 15.95 BDT.

As people are loosing 1.3 man-hour per day, one person is loosing 20.74 BDT everyday. Number of people in Dhaka metropolitan is 12,797,394 [13]. So, per day we are loosing 26.54 crore BDT. Per annum we are loosing 7,177 crore of BDT. And according to Alam (2008), in whole Bangladesh we are loosing 11,763 crore of BDT due to traffic jam. It means Dhaka City it self is contributing 63\% of the total loss. This calculation of man-hours is also known as VOT (Value of Travel Time Savings).

\subsubsection{Extra Transportation Cost}

Transportation cost of people of Dhaka is on an average 75.93 BDT. So, if their staying time in the traffic is less then definitely the cost will be lower. This is called VOT, value of travel time savings. More details will be discussed in the economic evaluation section later on. For urban we do not have any research on VOT in Bangladesh. For few areas in rural we have VOT.

\subsubsection{Extra Fuel Consumption}

Due to traffic jam per annum extra fuel consumption cost is 11,228 crore BDT [24] which is enormous amount of money for a least developed country like Bangladesh. Bangladesh government is buying this extra amount of fuel with hard cash. This is considered a national loss.

\subsubsection{Vehicle Operating Cost}

Every car has a running cost. Vehicle operating cost is directly proportionate to traffic jam. Like, if there is traffic jam, then the vehicle operator has to push the break and accelerator frequently. So, the life time of those will be less. Fuel consumption will continue if you are even in the jam and your car is on. So, Traffic jam actually increases VOC.

\subsubsection{Miscellaneous cost}

For serious patients, it is life and death situation in a traffic jam. It may happen that he is the only earning member of that family and due to traffic jam, he might be no more. And at that time the loss of the family can never be measured in money.

\subsection{Impact on Health}

Due to heavy traffic jam, the main sufferers are -

a. General people, and 
b. Vehicle operators.

\subsubsection{Sufferings of General People}

$73 \%$ of people in Dhaka City are suffering some kind of physical or mental discomfort due to traffic jam. It is very alarming.

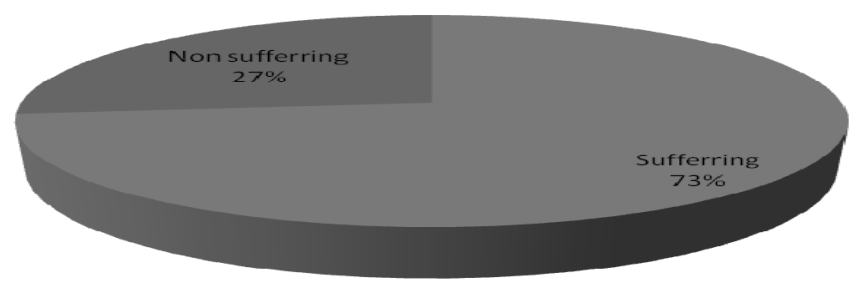

Figure 8. Percentage of people that are suffering discomfort due to traffic jam

People are suffering in many ways due to staying in traffic jam. Few main ways of sufferings that we have got from our survey are -

1) Breathing problem,

2) Headache,

3) Mental stress,

4) Hearing problem,

5) Unexpected sweating,

6) Tiredness, and

7) Eye problem.

From figure 9, it is apparent that people are mostly suffering from breathing problems (26\%) due to traffic jam. After that a big portion of people are suffering from headache (20\%) and mental stress (15\%). Hearing problem, Unexpected sweating, Tiredness and Eye problems are also very prominent among people who stay a longer period of time in traffic jam.

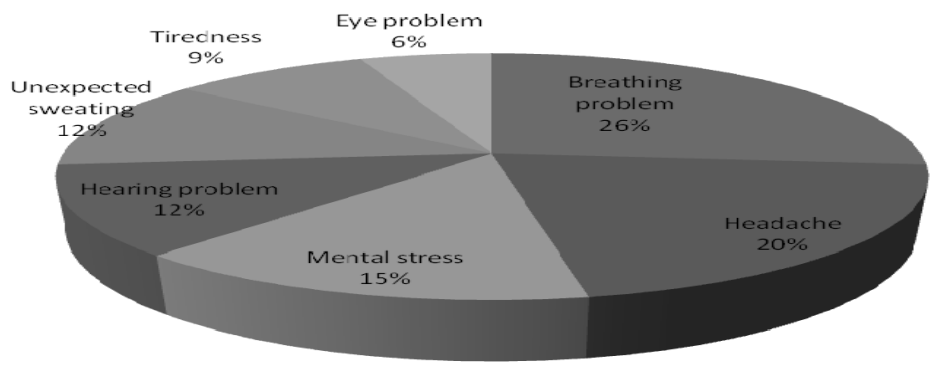

Figure 9. Discomfort that general people are suffering due to traffic jam

\subsubsection{Breathing Problem}

People suffer from breathing problem due to traffic jam. It happens that people due to smoke people cannot breathe or they have to breathe polluted gas. Frequent inhaling of polluted gas causes asthma. People suffer cannot breathe normally. 


\subsubsection{Headache}

Longer stay in traffic cause headache to many people. Continuous horn creates headache. And if same thing keep happening 5 days a week, anyone will have a chronic headache. As a result many people of Dhaka City has got a gift headache from traffic jam.

\subsubsection{Mental Stress}

Due to traffic jam, people get late in their appointments. This gives people a continuous mental stress. And taking this mental stress day by day, people get heart diseases, mental weakness and many other symptoms of weak hearts.

\subsubsection{Hearing Problem}

Due to heavy horn at the time of traffic jam, people suffer problem in hearing. Staying in the traffic for a long time makes a people unable to hear clearly for a few minutes. If this continues, the hearing problem might be permanent.

\subsubsection{Unexpected Sweating}

Due to staying in the traffic people sometime suffer from excessive sweating. As in the traffic there is smoke everywhere, the situation gets hotter. Some people who cannot bear hot, they start sweating heavily. And this heavy sweating some time causes heart attack.

\subsubsection{Tiredness}

Getting home from the office by passing through heavy traffic makes everyone tired. And due to this tiredness, no one can concentrate well in his family life. People get angry at smaller things.

\subsubsection{Eye Problem}

Due to staying in traffic jam, people's eyes come to contact of smoke. And this smoke cause pain in the eyes. Sometimes people tear in the jam automatically. People get burning eyes.

Except the above problems people also suffer from some other kinds of problems. Though few but worth mentioning physical problems that people also suffer for traffic jams are given below:
1) Suffocation,
2) Respiratory problem,
3) Puking,
4) Heart disease,
5) Fever,
6) Dust allergy,
7) Digestion problem, and
8) Dehydration.

\subsubsection{Sufferings of Vehicle Operators}

Among vehicle operators $30 \%$ of them are suffering from physical discomfort and $70 \%$ have told that they are not feeling any difference.

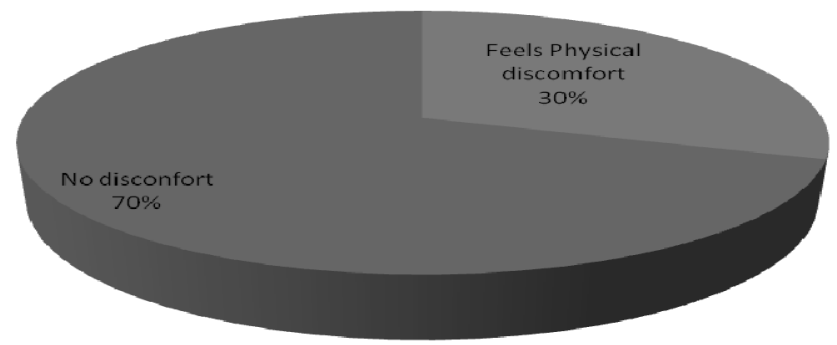

Figure 10. Percentage of vehicle operators that are suffering physical discomfort 
The ways of sufferings for the vehicle operators are almost similar to other people. The main sufferings are listed below:

1) Headache,

2) Pain in the body, and

3) Excessive Sweating.

Headache is the most common form of suffering from the vehicle operators. $50 \%$ of the sufferers are sufferings from headache. $33 \%$ are suffering from Pain in the body due to longer stay in the vehicle. $17 \%$ of sufferings come in the form of excessive sweating.

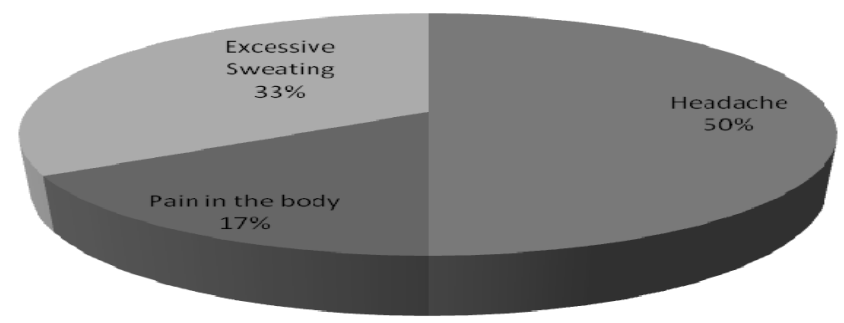

Figure 11. Ways of suffering of vehicle operators due to traffic jam

\subsubsection{Headache}

Longer stay in traffic cause headache to vehicle operators. Continuous horn creates headache. And if same thing keep happening 5 days a week and almost 12 hours in the street anyone will have a chronic headache. As a result vehicle operators of Dhaka City have got a chronic headache from traffic jam.

8.2.2.2 Pain in the body

Due to traffic jam, Vehicle operators get very little break. They have to stay tight in the traffic jam. So, trip after trip sitting in the same arrangement makes them feel pain in the back.

\subsubsection{Excessive Sweating}

Due to staying in the traffic like general people, vehicle operators also sometime suffer from excessive sweating. As in the traffic there is smoke everywhere, the situation gets hotter. Vehicle operators who work 12 hours a day, they start sweating heavily. And this heavy sweating some time causes heart attack.

\subsection{Impact on Environment}

Traffic jam causes environment pollution in two main ways. It causes -

a. Sound pollution, and

b. Air pollution.

\subsubsection{Sound Pollution}

Few findings of sound pollution and its effect (Dey et al, 2002) on the people of Dhaka city is given below:

$97 \%$ of students reported that their studying is disrupted by horns.

$86 \%$ of the general population consider noise pollution a big problem; only $1 \%$ said it is not a problem.

Among the general population

$78 \%$ experience aggravation,

$71 \%$ experience headaches,

$49 \%$ bad temper,

$43 \%$ difficulty concentration and trouble sleeping, and

$33 \%$ experience hearing problems from sound pollution.

$45 \%$ of drivers say they honk in traffic jams. 
The general public strongly support actions to reduce noise pollution, with the vast majority supporting improved traffic control, banning industrial activity and brick breaking machines in urban areas, placing limits on the decibels allowed in different areas, and banning miking for processions, advertising, and election campaigns.

\subsubsection{Air Pollution}

Traffic jam introduces air pollution through SOx, NOx, COx (SO2, CO, CO2, N2O, NO2). And in the traffic jam, when vehicles stop for a longer periods of time and their engine is on, they emit SOx, NOx much which are lighter than air but very dangerous for our health and they even can cause death.

SPM(Suspended Particle Matter) which are normally emitted from exhaust tail. Due to less burning some unburnt particle gets out from the exhaust tail which causes cancer. People at CNG level suffer the most. Because the unburnt fuel is heavier than air, so they want to go down, but they cannot go down because of repulsion of the road.

SPM are normally positively charged, and due to friction between the tyre and road all day long, the road become positively charged also. So, it creates repulsion which makes the particle to keep in such a level which is easier to inhale by human. People in the afternoon suffer most.

Due to building around two sides of the road, SPM got stuck. It creates a deadly canal. We need cross ventilation so that air can drive SPM away or make it diluted. But, there are very few space left both sides of the road. As a result we are keeping these particles in our way which is deadly for children and even for older ones too.

\section{Solutions of Traffic Jam in Dhaka City}

The solution of traffic jam in Dhaka City is not easy. We will discuss solutions from three points of view.

a. General people's point of view,

b. Vehicle operators point of view,

c. Expert's point of view.

\subsection{Solution Provided by General People}

The main solutions provided general people are -

1) Awareness building,

2) Flyovers,

3) Public transportation,

4) Strict traffic law implementation,

5) Office/School time scheduling,

6) Subway, and

7) Removing rickshaw.

So, most of the people think that traffic jams can be reduced by creating proper awareness. Other than that more flyovers, more public transportation, strict law enforcement can reduce traffic jam.
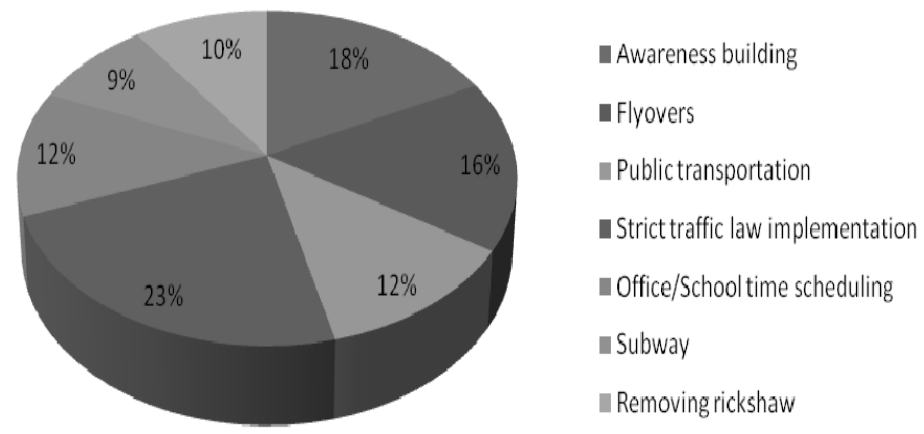

Figure 12. Solution provided by general people for traffic jams 


\subsubsection{Awareness Building}

To reduce traffic congestion in Dhaka City, the most vital prerequisite, is the development of public awareness. Unless and until people change their perception and develop a mind to abide traffic rules, whatever strategy Government takes, that will not work properly. Law-abiding consciousness, good-intention and sincere co-operation can remarkably reduce traffic jam in Dhaka city.

\subsubsection{Flyovers}

Many people, $16 \%$, think that flyovers can be a possible solution to the current traffic condition of Dhaka city. If flyovers can be construction in the main roads then the vehicles can move on the roads as well as on the flyovers at the same time. That will surely reduce the load on the busy roads.

\subsubsection{Public Transportation}

More people, $12 \%$, will be willing to travel through public transports rather than private cars if proper public transportation service can be offered. People think that public transport, like bus, can carry many passengers at the same time which will reduce the cost and time expense for them.

\subsubsection{Strict Traffic law Implementation}

23\% people think that traffic jam in Dhaka City can be reduced by implementing traffic law strictly. If all types of vehicle drivers follow the traffic rules properly then it can surely decrease the load on the road and improve the current scenario.

\subsubsection{Office/School Time Scheduling}

Many people, $16 \%$, think that flyovers can be a possible solution to the current traffic condition of Dhaka city. If flyovers can be construction in the main roads then the vehicles can move on the roads as well as on the flyovers at the same time. That will surely reduce the load on the busy roads. Government has successfully implement different timing schedule for schools of Dhanmondi area and that can be applied to all other areas as well. $12 \%$ people think that it will reduce the office and school time traffic load on the roads.

\subsubsection{Subway}

Subway can be a possible solution for a busy city like Dhaka which do not has the ability to provide wider road for the vehicles. Subway can provide underground access for the vehicles all over the city and reduce traffic jam.

\subsubsection{Removing Rickshaw}

Dhaka city has eighty-five thousand legal rickshaws whereas it has more than six lakh rickshaws. It is learnt that more one lakh is going to join them before the Eid. Still it becomes awfully difficult to get a rickshaw during office going and coming time. Rickshaw pullers don't want to go to the passengers' expected places. They just wait in particular places to move to some particulars areas causing traffic jam as well as tremendous problems to the passengers. $18 \%$ people think that rickshaw should be removed, at least from the main roads, to improve the current traffic condition. They also think some more steps can be taken to reduce traffic jams. Like -

1) Sky train,

2) Restriction/ more tax on private vehicle,

3) Mandatory school bus, and

4) Modern equipped signalling system.

\subsection{Solution Provided by Vehicle Operators}

The main solutions provided vehicle operators are -

1) Strict traffic law implementation,

2) Flyovers,

3) Dedicated road for vehicles, and

4) Decentralization. 


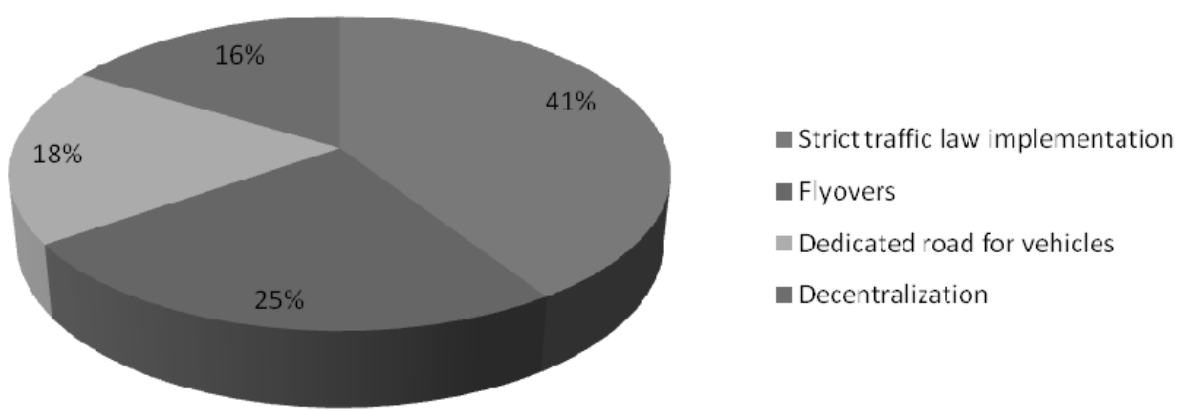

Figure 13. Solutions provided by vehicle operators

\subsubsection{Strict traffic Law Implementation}

41\% vehicle operators think that traffic jam in Dhaka City can be reduced by implementing traffic laws strictly. If all types of vehicle drivers follow the traffic rules properly then it can surely decrease the load on the road and improve the current scenario.

\subsubsection{Flyovers}

Many drivers, 25\%, think that flyovers can be a possible solution to the current traffic condition of Dhaka city. If flyovers can be construction in the main roads then the vehicles can move on the roads as well as on the flyovers at the same time. That will surely reduce the load on the busy roads.

\subsubsection{Dedicated Road for Vehicles}

Dhaka is a city of heterogeneous vehicles. Human puller to latest model automobile, mechanical to non-mechanical, slow to fast-moving, nothing left on the road of Dhaka. It is quite difficult to control all these vehicles on the same road as they have different speed capacity. There should be dedicated roads for difference types of vehicles.

\subsubsection{Decentralization}

According to the drivers, people are normally moving from their home to the offices, schools, industries and markets. Dhaka city cannot provide adequate road facility for all this activities. $16 \%$ drivers think that Dhaka should be decentralized and major offices, industries like Tanneries, Cantonment, etc should be moved away from this busy city to reduce load on the roads.

\subsection{Solution Provided by Experts}

Experts mainly suggest solution in term basis. There should be dedicated roads for difference types of vehicles. They think it should be -

a. Short term basis (less than 5 years),

b. Mid term basis (5 to 10 years) and

c. Long term basis (more than 10 years).

\subsubsection{Short Term Solutions}

The main short term solutions are stated below:

i. Increasing pedestrian facilities,

ii. NMT (Non Motorized Transport) free road,

iii. Maximum use of road width,

iv. Banning unauthorized parking,

v. Controlling road side activities,

vi. Modern signalling system,

vii. Speed wise dedicated road for vehicles,

viii. Car free days,

ix. High Parking charge, 


\section{x. Discourage private cars,}

xi. Effective use of underpass and over bridge,

xii. School bus,

xiii. Time rescheduling,

xiv. TIA (Traffic Impact Assessment) before plan pass of any construction,

$\mathrm{xv}$. Increase the number of public vehicle, and

xvi. Training of traffic polices.

\subsubsection{Increasing Pedestrian Facilities}

According to the survey conducted, about 50\% people in Dhaka city will like to move from one place to another on foot. But the road side condition is not appropriate for them to walk. If Government can improve the pedestrians' facility, load on the road will be reduced and people will be encouraged to walk to reach nearby destinations.

\subsubsection{NMT (Non Motorized Transport) Free Road}

Dhaka is a city of heterogeneous vehicles. Human puller to latest model automobile, mechanical to non-mechanical, slow to fast-moving, nothing left on the road of Dhaka. It is quite difficult to control all these vehicles on the same road as they have different speed capacity. The main roads can be made NMT free road to reduce traffic jam.

\subsubsection{Maximum Use of Road Width}

Dhaka City has very inadequate road networks. For a standard city, where the minimum road requirement is $25 \%$, Dhaka has only $7.5 \%$ road of its total area. To reduce traffic jam, maximum use of road width should be ensured.

\subsubsection{Banning Unauthorized Parking}

25 percent place should be for the movement and parking of vehicles in a city whereas Dhaka city has only 7 percent such place invoking a natural cause for being traffic jam. It is very practical that the city does not have sufficient place for allowing the vehicles freely. Unauthorized parking should be banned all over the city.

\subsubsection{Controlling Road Side Activities}

For a standard city, where the minimum road requirement is $25 \%$, Dhaka has only $7.5 \%$ road of its total area. $30 \%$ of this $7.5 \%$ road is also occupied by the hawkers, salesman and shopkeepers. A significant portion is occupied by construction materials and waste-containers of the City Corporation. As a result, vehicles do not get sufficient space to move on. Such road side activities creating problem for the traffic should be controlled.

\subsubsection{Modern Signalling System}

Traffic management system of Dhaka city is not automated and well-equipped. All the junctions are not facilitated with signal lights. Where there are lights, most often those remain out of order. Moreover, uneven flow of vehicles from different directions reduces the effectiveness of traffic signals. Modern signalling system should be introduced.

\subsubsection{Speed Wise Dedicated Road for Vehicles}

There should be dedicated roads for difference types of vehicles with different speed. The roads which see both mechanized and non-mechanized vehicles use must make exclusive space for non-mechanized vehicles. It will ensure both easy and quick passage and movement of mechanized vehicles. Again, the accentual casualties will get lessened. Now what happens, the non-mechanized vehicles and mechanized ones go side by side causing disturbance to one another and one can move freely. A little touch or hassle invites serious hassle, crowd and chaos causing serious traffic jam. So, these roads must be separated by railings so that both rickshaws and buses and cars can move according to their own speed.

\subsubsection{Car Free Days}

Mayor of one of the states in Colombia decided to declare one day of the month as a car free day and that reduced the load on the road. This strategy can be applied in Dhaka to improve the traffic condition.

\subsubsection{High Parking Charge}

Limited parking arrangement is another major cause of excessive traffic in Dhaka City. It has become a regular practice to park the car on road. Even during rush hours, people are seen loading and unloading their vehicles on 
a busy road. City transports also stop here and there without any valid reason. High parking charge should be applied to reduce this practice.

\subsubsection{Discourage Private Cars}

A study states that a bus can provide space for 30 people more than a car but occupy only thrice the area than a car. It will be very helpful to reduce load on the road by discouraging private cars. Many buses with many stations should be introduced. It will lessen people's dependence on small and private vehicles. Private vehicles kill much of the limited space of the city. If big and luxurious buses can be introduced, the intensity of traffic jam must be thinner and the people will lose interest in rickshaws because of comfort and cheapness.

\subsubsection{Effective Use of Underpass and Over Bridge}

There are some underpasses and over bridges in Dhaka city which were built to provide alternate walkways for people to cross the roads. Effective use of this can improve the current road condition by reducing number of people walking through the busy roads. A study states that a bus can provide space for 30 person more than a car but occupy only thrice the area than a car. It will be very helpful to reduce load on the road by discouraging private cars. Many buses with many stations should be introduced. It will lessen people's dependence on small and private vehicles. Private vehicles kill much of the limited space of the city. If big and luxurious buses can be introduced, the intensity of traffic jam must be thinner and the people will lose interest in rickshaws because of comfort and cheapness. In all the busy points there must be foot over bridges and no pedestrians will be allowed to cross the roads where foot over bridges are constructed. All the news media, police, schools, market, garment workers all will get the message and briefing from their attached and concerned authorities to use foot over bridge. Many busy points of the city don't have foot over bridges. Pedestrians are to cross the road every minute making the processions of vehicles stopped and stranded. Its effect spreads several miles. Again, there are many over bridges which are not used by the pedestrians because of habit, lack of awareness and law enforcement. From now on it must be made compulsory to use foot over bridges and the remaining crowd and busy point must see the immediate construction of foot over bridges.

\subsubsection{School Bus}

All the schools and colleges will have to introduce their own transports for their students. When many students go to schools and colleges by personal transport and rickshaws, a serious traffic jam occurs around the institutions and its impact influences the adjoining areas of the institutions. Everyday hundreds of guardians stand beside the road with their kids to request the rickshaws and CNGs with much tension as school gates will be closed. During the examinations the situation goes further worse.

\subsubsection{Time Rescheduling}

During office going and coming time, hundreds and thousands of passengers keep stranded in numerous spots of the city. Law must be enacted to enhance the facilities of the passengers as well as to lessen the knot of traffic jam. Time of the offices and schools should be rearranged to reduce the load on the roads.

\subsubsection{TIA (Traffic Impact Assessment) before Pass Plan of Any Construction}

Before starting a construction it is mandatory to pass the plan from RAJUK. The concerned authority should check the Traffic Impact Assessment (TIA) of the plan to evaluate the impact of the construction on the traffic of nearby area.

\subsubsection{Increase the Number of Public Vehicle}

Public transport system in Dhaka city is not adequate and properly-routed. Instead of big and spacious buses, presence of large number of mini-buses and private vehicles can only contribute to carry few passengers, but not to reduction of traffic congestion. Number of public transport should be increased to reduce traffic jam.

\subsubsection{Training of Traffic Polices}

Dhaka city authority does not have sufficient and well-trained human resources. Four thousand officers work in two shifts- morning and afternoon. Due to administrative and other involvement, only fifteen hundred officers can be engaged in one shift to control the movement of millions of people and vehicles in Dhaka City. This figure is quite insufficient to manage the existing traffic scenario.

\subsubsection{Mid Term Solutions}

Mid-term solutions according to experts are given below:

i. BRT (Bus Rapid Transit), 
ii. Elevated express highway,

iii. Only one authority to control traffic of Dhaka City,

iv. Construction of roads through East-West,

v. Adequate parking facilities,

vi. Circular embankment-cum-road along periphery of Dhaka City,

vii. Connecting the missing links of important roads, and

viii. Improving the efficiency of railways and river ferries.

\subsubsection{BRT (Bus Rapid Transit)}

BRT can be introduced to provide alternative transport facility for the citizen of Dhaka city. There should be a separate lane for the public busses only. It will be very helpful to reduce load on the road. A study states that a bus can provide space for 30 people more than a car but occupy only thrice the area than a car. Many buses with many stations should be introduced. It will lessen people's dependence on small and private vehicles. Private vehicles kill much of the limited space of the city. If big and luxurious buses can be introduced, the intensity of traffic jam must be thinner and the people will lose interest in rickshaws because of comfort and cheapness.

\subsubsection{Elevated Express Highway}

Dhaka city does not have enough capacity to provide road facility for the excess vehicles and as a result traffic jam is a common scenario. It is not possible to enlarge the width the roads due to road side constructions like buildings, offices, markets, etc. One possible solution can be developing elevated express highway to provide access for the vehicles to avoid busy roads and move through this highways.

\subsubsection{Only One Authority to Control Traffic of Dhaka City}

There are about organizations in Dhaka city that have at least some authority to work and control traffic of Dhaka city. Very often some problems and confusions are created among them regarding their duties and responsibilities. There should be one concerned authority to develop law and policy and control traffic of Dhaka.

\subsubsection{Construction of Roads through East-West}

Various developments of roads were done in the North-South region of Dhaka city but the East-West side do not have that much advanced transport facilities. Construction of roads through East-West can reduce the vehicle load on the North-South region and improve the current scenario. These roads can also be used as a bypass to avoid the busy roads of Dhaka city.

\subsubsection{Adequate Parking Facilities}

Adequate parking facilities should be made available in Dhaka city. 25 percent place should be for the movement and parking of vehicles in a city whereas Dhaka city has only 7 percent such place invoking a natural cause for being traffic jam. It is very practical that the city does not have sufficient place for allowing the vehicles freely. Unauthorized parking should be banned all over the city.

\subsubsection{Circular Embankment-Cum-Road along Periphery of Dhaka City}

Dhaka city is surrounded by three important rivers namely Buriganga river, Turag river and Balu river. Under Flood Action Plan (FAP-8B) project, along the western portion of Dhaka city, the western embankment cum road has already been constructed. Recently government will take the project under FAP-8A which leads to the construction of eastern embankment cum road along the eastern portion of the city. If these two portions are connected then it will act as an important circular by-pass road along the periphery of the city.

\subsubsection{Connecting the Missing Links of Important Roads}

There are some important areas in Dhaka city which do not have links with nearby important roads. People in that particular locality have to travel more to reach their destinations. Connecting the missing links of important roads can save both time and money of people and improve the current traffic conditions of the city.

\subsubsection{Improving the Efficiency of Railways and River Ferries}

Everyday Kamalapur Railway Station is experiencing movement of 74 trains to and from Dhaka. On an average, it takes five minutes to get the clearance for each crossing. Thus in one crossing, everyday the vehicles stop for six hours that is really difficult to offset. Waterways can be used as an alternate transportation passage. Efficiency of the railways and river ferries should be improved. 


\subsubsection{Long Term Solution}

Long term solutions that experts suggest are -

1) Environment sustainable transport,

2) MRT (Mass Rapid Transit), and

3) Grade separated road network.

\subsubsection{Environment Sustainable Transport}

Experts suggest implementing environment sustainable transport to provide transportation facilities to people as well as not to harm the environment. It is essential to minimize the negative impact of transport sector on environment and create increased transport-related environmental awareness in society. While thee transport sector has played a vital role in supporting the economic and social development of Dhaka, it has also brought with it environmental concerns and consequences that need to be addressed. The success achieved in Dhaka with the replacement of highly polluting two-stroke engine version of the three wheeled auto-rickshaws with CNG versions. The current heavy reliance on walking and rickshaw as a means of transport in Dhaka is environmentally beneficial and should not be discouraged.

\subsubsection{MRT (Mass Rapid Transit)}

To place all the reliance on one system (namely the BRT system) only which has a limited capacity could place the city at risk. Hence a blend of BRT and Metro is preferred to a single system based on BRT alone. As system capacities are exceeded, the ultimate system will need to include a METRO system. The first priority is to maximize the existing resources by a strong traffic management system. This should be complemented by an appropriate MRT system. It is also recognised that in the longer term, BRT will not be the ultimate solution for Dhaka city which will exceed 36 million populations.

\subsubsection{Grade Separated Road Network}

Dhaka city does not have the capacity to provide enough road facilities for the huge number of people residing in the city. There can be alternative ways offered by the Government for the people to move through the city. Grade separated road network can be established for this purpose. Current road condition can be improved along with creating fly overs, elevated highways above the roads and subways, METRO under the roads. These 3 types of road facilities can be implemented to solve the current traffic jam problem by providing more transport passages.

\section{Conclusion \& Recommendation}

Dhaka City is the capital of Bangladesh which is a least developed country. It is very important for this City to take vital role in the economy of Bangladesh. But now due to traffic jam, this City is causing the major loss in the economy of Bangladesh. By reducing traffic jam, this city can play a very important role for the country and at the same it can also bring relief and peace for the citizens by ensuring healthy environment free from noise and pollution. To ensure a healthy generation, traffic jam must be reduced. There are lots of solutions. Some are short term and some are long term basis. We need to work on the basis of long term plan and at the same time take care of short term solution to remove current discomforts or problems. It needs a balance so that to fulfil too much short term solution we do not ruin the long term plan. Our focus should be the solution of traffic jam, strong economy and healthy environment.

We have already shown solutions of traffic jam from different perspectives. And there are some common solution depicted by general people, vehicle operators or experts. So, we are summarizing the solutions in one directed way so that our focus can be unidirectional. We want to reduce traffic jam using resources that are within our limit.

In the following we are showing some short term strategies that can be taken care of -

i. Increasing pedestrian facilities,

ii. Maximum use of road width,

iii. Controlling road side activities,

iv. Modern signaling system,

v. Speed wise dedicated road for vehicles,

vi. Car free days,

vii. High Parking charge, 
viii. Discourage private cars,

ix. Time rescheduling,

x. TIA (Traffic Impact Assessment) before plan pass of any construction,

xi. Increase the number of public vehicle, and

xii. Training of traffic polices.

Similarly we can work on some midterm strategies, which can be taken care of within 5 to 10 years, are given below:

i. BRT (Bus Rapid Transit),

ii. Central authority to control traffic of Dhaka City,

iii. Construction of roads through East-West,

iv. Adequate parking facilities,

v. Circular embankment-cum-road along periphery of Dhaka City,

vi. Connecting the missing links of important roads, and

vii. Improving the efficiency of railways and river ferries.

For long term solution we have to think of implementing -

1) Environment sustainable transport,

2) MRT (Mass Rapid Transit), and

3) Grade separated road network.

If we look at STP, it is obvious that if we go for Metro, Bangladesh government has to give annual subsidy. But for a country like us it would be very difficult to provide a service which is beyond our potential financial scope and needs subsidy. We have to think within our limitations. So, we recommend no metro. It means we are left with 4 strategies only. Among these four as we are unwilling to provide minimal annual subsidy if it ensures other greater benefits, we are left with only 2 alternatives. Among this two definitely we need advanced level of road development within the City of Dhaka. So, we can go for the strategy given below:

Advanced level of road improvement, All BRT, No Metro

It needs initial investment of USD 3.2 billion, which is within potential financial capability and needs small operating subsidy for BRT. But at the same time it ensures -

1) Highest combined travel speed, and

2) Highest for Mobility/ Accessibility goal.

These mean efficiency improvement, more output and more revenue generation. We hope that by implementing these plans through proper care, definitely we can ensure traffic jam free and environment friendly Dhaka City.

\section{References}

Ahmed, S. U. (1986). Dacca: A Study in Urban History and Development. Curzon Press.

Alam, J. B. (2003). Air Transport in Islam, Sirajul. Banglapedia: National encyclopedia of Bangladesh. Dhaka: Asiatic Society of Bangladesh. Retrieved from http://banglapedia.search.com.bd/HT/A_0133.htm. (October 18, 2011).

Alam, J. B. (2008). Concerns, challenges \& options for suitable in developing countries. Sustainable transport for development Countries: Concerns, Issues \& Options.

Bari, M. F. (2008). Feasibilty Study for Development of Circular Waterways around Dhaka City. Department of Water Resources Engineering, Bangladesh University of Engineering and Technology.

Dey, A. R., Kabir. N., \& Efroymson. D. (2002). Noise Pollution: Research and Action, Work for a Better Bangladesh.

Economic and Social Commission for Asia and the Pacific. (2005). Dhaka: Asian Highway Handbook. United Nations Economic and Social Commission for Asia and the Pacific, United Nations Publications.

Fioravante, E. F., \& Fígoli, M. G. B. (2009). Environmental impact due to automobile use. XXVI IUSSP International Population Conference, Morocco. 
Karim, M. M. (1997). Traffic Pollution in Bangladesh \& Metropolitan Dhaka a Preliminary Investigation. 90th Annual Meeting of A\&WMA, Toronto, Canada.

Kazi, N. (2003). A brief note on the Dhaka A Transport Project. Unpublished Phase-I project report.

Khan, M. A. (2007). When shall we get rid of Dhaka city traffic jam? Bitter Truth. The Daily Star, Bangladesh.

Khandoker, N., \& Rouse, J. (2004). Urban development and livelihoods of the poor in Dhaka. 30th WEDC International Conference, Vientiane, Lao PDR.

Laskar, R. (2007). Rickshaw pullers get licences. The Daily Star. Retrieved from http://www.thedailystar.net/2007/03/04/d703042503132.htm. (November 12, 2011)

Lawson, A. (2002). Good times for bourgeois Bangladeshis. BBC News. Retrieved from http://news.bbc.co.uk/2/hi/south_asia/2018535.stm. (November 10, 2011)

McAdam, M. (2004). Bangladesh. Lonely Planet, 66.

McGee, T. (2006). Urbanization Takes on New Dimensions in Asia's Population Giants. Population Reference Bureau. Retrieved from http://www.prb.org/Articles/2001/UrbanizationTakesonNewDimensionsinAsiasPopulationGiants.aspx. (October 25, 2011)

Prskawetz, A., Leiwen, J., \& O’Neill, B. C. (2004). Demographic composition and projections of car use in Austria. Vienna Yearbook of Population Research. Vienna: Austrian Academy of Sciences, Vienna Institute of Demography, 175-201.

Rahman, Mushfiqur. (2003). "Compressed Natural Gas" in Islam, Sirajul. Banglapedia: National encyclopedia of Bangladesh. Dhaka: Asiatic Society of Bangladesh. Retrieved from http://banglapedia.search.com.bd/HT/C_0326.htm.

Shovan, S. S. A. (2008). Fuel Consumption and Environmental Impact of Rickshaw Bans in Dhaka. Voice of South: Online Platform for South Asian Rural Community.

Shuichi, M., \& Hironao, K. (2003). A Study on the Traffic Impacts in City Traffic Consideration of the Value of Time about Streetcar. Journal of Nippon Kikai Gakkai Kotsu, Butsuryu Bumon Taikai Koen Ronbunshu (Japan), 12, 403-406.

Statistical Pocket Book. (2008). Bangladesh Bureau of Statistics.

Ullah, A. H. J. (2001). Dhaka’s hopeless traffic jams stop everything but the clock! The Dhaka Diary.

YI, Z. (1991). Family dynamics in China: a life table analysis. Wisconsin: The University of Wisconsin Press. 